\title{
The approach of physiatrists to low back pain across Europe
}

Fitnat Dincer ${ }^{\mathrm{a}, *}$, Serdar Kesikburun ${ }^{\mathrm{b}}$, Oya Ozdemir ${ }^{\mathrm{a}}$, Evren Yaşar $^{\mathrm{b}}$, Susana Munoz ${ }^{\mathrm{c}}$, Raquel Valero ${ }^{\mathrm{c}}$, Alvydas Juocevidius $^{\mathrm{d}}$, Michail Quittan ${ }^{\mathrm{e}}$, Aet Lukmann ${ }^{\mathrm{f}}$, Andreas Winkelman $^{\mathrm{g}}$, Anita Vetra ${ }^{\mathrm{h}}$, Björn Gerdle ${ }^{\mathrm{i}}$, Carlotte Kiekens ${ }^{\mathrm{j}}$, Catarina Aguiar Branco ${ }^{\mathrm{k}}$, Eimear Smith ${ }^{\mathrm{l}}$, Mark Delargy ${ }^{\mathrm{m}}$, Elena Ilieva $^{\mathrm{n}}$, François Constant Boyer ${ }^{\mathrm{o}}$, Frane Grubisic ${ }^{\mathrm{p}}$, Hermina Damjan $^{\mathrm{q}}$, Liisamari Krüger ${ }^{\mathrm{r}}$, Markku Kankaanpääs, Erieta Nikolikj Dimitrova ${ }^{\mathrm{t}}$, Marina Delic ${ }^{\mathrm{u}}$, Milica Lazovic ${ }^{\mathrm{v}}$, Natasa Tomic ${ }^{\mathrm{w}}$, Nikolaos Roussos $^{\mathrm{x}}$, Xanthi Michail ${ }^{\mathrm{y}}$, Paolo Boldrini ${ }^{\mathrm{z}}$, Stefano Negrini ${ }^{\mathrm{aa}}$, Peter Tan $\mathrm{cc}^{\mathrm{bb}}$, Piotr Tederko ${ }^{\mathrm{cc}}$ and Yvona Angerova ${ }^{\mathrm{dd}}$

${ }^{a}$ Department of Physical Medicine and Rehabilitation, School of Medicine, Hacette e University, Ankara, Turkey ${ }^{\mathrm{b}}$ Department of Physical Medicine and Rehabilitation, Gülhane School of Medicine. University of Health Sciences, Gaziler Physical Therapy and Rehabilitation Research and Training Hospit at, Ankara, Turkey

${ }^{c}$ Department MedicinaFisica y Rehabilitacion, Universidad Complutense, L. aririd, España

${ }^{\mathrm{d}}$ Rehabilitation, Physical and Sports Medicine Center, Medical Fac ilty, Vuinius University, Vilnius, Lithuania 'Institute of PMR, Kaiser-Franz-Joseph-Hospital, Vienna, Austria

${ }^{\mathrm{f}}$ Department of Sports Medicine and Rehabilitation, University of Ta tu, Tartu, Estonia

${ }^{g}$ Klinik und Poliklinik für Physikalische Medizin und Rehabili ation, München, Germany

${ }^{\mathrm{h}}$ National Rehabilitation Center, Neurological Rehabilitation, Jurmala, Latvia

i Pain and Rehabilitation Center, Department of Medical und Health Sciences, Linköping University, Linköping, Sweden

¡Physical and Rehabilitation Medicine, Universit stospitals Leuven, Holsbeek, Belgium

${ }^{\mathrm{k}}$ Rehabilitation Medicine Department, Hospitu' Sal Sebastião, CHEDV, Santa Maria da Feira, Portugal

${ }^{1}$ National Rehabilitation and Mater Miseric rrdiaé University Hospital, Dublin, Ireland

${ }^{\mathrm{m}}$ National Rehabilitation Hospital, Dun Q.cghaire, Co., Dublin, Ireland

${ }^{\mathrm{n}}$ Department of Physical and Rehabi lîn atıon Medicine, Medical University Hospital, Plovdiv, Bulgaria

${ }^{\circ}$ Department of Physical and Reh ${ }^{1}+i_{i}$ tation Medicine, Champagne Ardenne University Reims, Reims, France

${ }^{\mathrm{p}}$ Department of Rheumatology P,weccal Medicine and Rehabilitation, School of Medicine, University of Zagreb,

University Hospital Center "So ctveMilosrdnice", Zagreb, Croatia

${ }^{a}$ Institute for Rehabilitation, Ljubljana, Slovenia

rOrton Rehabilitation C^nt e, Orton Orthopaedic Hospital, Helsinki, Finland

${ }^{\mathrm{S} D e p a r t m e n t}$ of Physical and Rehabilitation Medicine, Tampere University Hospital, Tampere, Finland

${ }^{\mathrm{t}}$ Institute for Physical Medicine and Rehabilitation, Medical Faculty, Ss Cyril and Methodius University of Skopje,

Skopje, Republic of Macedonia

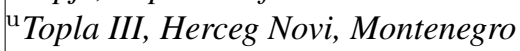

${ }^{v}$ Faculty of Medicine Belgrade and Institute for Rehabilitation Belgrade, Belgrade, Serbia

"Institute for the Physical Medicine and Rehabilitation "Dr. MiroslavZotovic", Banjaluka, Republika Srpska

×Asklipeion General Hospital, Athens, Greece

*Corresponding author: Fitnat Dincer, Hacettepe University, School of Medicine, Department of Physical Medicine and Rehabilitation, Ankara, Turkey. Tel.: +90 (312) 30515 74; E-mail: fitnatdincer@gmail.com. 
${ }^{y}$ ATEI, Athens, Greece

${ }^{2}$ Rehabilitation Department, Azienda ULSS 2, Treviso, Italy

${ }^{\text {aa } U n i v e r s i t y ~ o f ~ B r e s c i a, ~ I R C C S ~ D o n ~ G n o c c h i ~ M i l a n, ~ C l i n i c a l ~ a n d ~ E x p e r i m e n t a l ~ S c i e n c e s, ~ P h y s i c a l ~ a n d ~ R e h a b i l i-~}$ tation Medicine, Milan, Italy

${ }^{\mathrm{bb}}$ Pavol Jozef Safarik University in Kosice Faculty of Medicine, L. Pasteur University Hospital, Kosice, Slovak Republic

${ }^{\mathrm{cc}}$ Department of Rehabilitation, Medical University of Warsaw, Warsaw, Poland

${ }^{\mathrm{dd}}$ Department of Rehabilitation Medicine, General Teaching Hospital Prague, Prague, Czech Republic

\begin{abstract}
.
BACKGROUND: Low back pain (LBP) is the most common type of musculoskeletal pain, thus it is one of the most commonly encountered conditions in Physical and Rehabilitation Medicine. The physicians who are primarily responsible for the nonsurgical management of LBP are physiatrists.
\end{abstract}

OBJECTIVE: The present study aimed to investigate the approaches of physiatrists to low back pain across Europe. Preferences, tendencies, and priorities in the diagnosis, management, and treatment of LBP, as well the epidemiological data pertaining to LBP in PRM practice were evaluated in this Europe-wide study.

METHODS: The study was conducted under the control of the European Society of Physical a d R ehabilitation Medicine (ESPRM) Musculoskeletal Disorders Research Committee. A total of 576 physiatrists from r 10 st Iuropean countries participated in the survey.

RESULTS: The results show that physiatrists frequently deal with patients with $L F P_{1} \mathrm{n}$ their daily practice. Most patients are not referred to other departments and are treated with various conservative methods. Less than one-fifth of patients are primarily referred for surgery. The physiatrists believe that a clear diagnosis to accol nt for cases of low back pain is rarely established. The most common diagnosis is discopathy. History and physical examination main the most valuable clinical evaluation tools for low back pain according to physiatrists. Less than half the patients 1 qu re a magnetic resonance imaging. Non-steroidal anti-inflammatory drugs are the most commonly prescribed drugs 1 or 1 w back pain. Exercise, back care information, and physical therapy are the preferred conservative treatments. More tha $\eta$ half of the physiatrists offer interventional treatments to patients with low back pain.

CONCLUSION: The present study is a preliminary report hat presents the attitudes of European physiatrists in the management of low back pain. Further researches are warranted to st ndardize the conservative management of LBP.

Keywords: Low back pain, physiatrist, conservat ve munagement, rehabilitation

\section{Introduction}

Low back pain (LBP) is the most common type of musculoskeletal pain [1] hus it is one of the most commonly encountered or ditions in Physical and Rehabilitation Medicine (PRM). Most people experience LBP at some point in life; the lifetime prevalence varies between $50 \%$ and $85 \%$ in epidemiological studies [2] and the annual prevalence is estimated at around $40 \%$ [3]. The Global Burden of Disease study reported that LBP is the highest ranked condition contributing to years lived with disability $[4,5]$. It is therefore a significant cause of disability and absence from work.

The physicians who are primarily responsible for the nonsurgical management of LBP are physiatrists. PRM is the specialism that deals with most stages in the management of LBP including the initial evaluation, differential diagnosis, planning appropriate nonsurgical treatments among the many options (patient education, exercise, physical modalities, drugs, interventional pain procedures, etc.), follow-up, and referral for surgical treatment if necessary. The present study aimed to investigate the approaches of physiatrists to low back pain across Europe. Preferences, tendencies, and priorities in the diagnosis, management, and treatment of LBP, as well as the epidemiological data pertaining to LBP in PRM practice were evaluated in this Europe-wide study.

\section{Methods}

\subsection{Study design and participants}

A cross-sectional descriptive survey was undertaken to define the clinical approach of European physiatrists to LBP. A total of 576 physiatrists from most European countries participated in the survey. The survey was 
carried out between October 2014 and October 2015. The study was conducted under the control of the European Society of Physical and Rehabilitation Medicine (ESPRM) Musculoskeletal Disorders Research Committee.

\subsection{Procedures}

An internet based-survey was prepared, and physiatrists from most European countries were invited to participate. National supervisors oversaw the distribution of the survey to physiatrists in their own country. Each national supervisor translated the survey to his or her own native language. The survey document was available to participants in both English and the native language. The survey was largely distributed via an online survey site (Survey Monkey ${ }^{\circledR}$ ). Any participant who could not access the online survey site was asked to complete a digital survey document. The responses in the digital survey documents were collected by email. The national supervisors submitted manually the data in the digital survey documents to the online survey site instead of the participants who could not access the online survey site. All the responses were collected from the online survey site.

\subsection{The survey}

The survey included 22 multiple choices quesine and took no more than $3 \mathrm{~min}$ to complete to en $\mathrm{ur}$. $\mathrm{d}$ herence. The questions were prepared by a $\mathrm{g}$ oun of senior physiatrists who each have at least $3 \%$ jears of experience in PRM. The first part of the irvy consisted of 6 questions related to the demogra phic characteristics of the participants including are, gender, job experience, academic degree, instit tio 1 , and working area. The second part incorporat $\$ 5$ questions relating to preferences for the asse sm nt, management, and treatment of LBP. Participants were asked about the number of patients with LBP seen per week, the established causes of LBP, preferred diagnostic methods, the rates and reasons for referral to another clinical department, the preferred treatment options including pharmacological, patient education, physical modalities, exercise, interventional procedures, and the scales [6-10] on LBP which were used most frequently was questioned. The number of structured choices varied according to the nature of the question. Some of the questions were open-ended.

\subsection{Statistical analysis}

Data analysis was performed with SPSS for Win-

\begin{tabular}{|c|c|}
\hline \multicolumn{2}{|l|}{$\begin{array}{c}\text { Table } 1 \\
\text { Participants' demographics }\end{array}$} \\
\hline & $\begin{array}{c}\text { Participants } \\
(n=576)\end{array}$ \\
\hline \multicolumn{2}{|l|}{ Sex } \\
\hline Male & $211(36.6 \%)$ \\
\hline Female & $365(63.4 \%)$ \\
\hline \multicolumn{2}{|l|}{ Age } \\
\hline 20-30 years & $59(10.2 \%)$ \\
\hline $31-40$ years & $179(31.2 \%)$ \\
\hline $41-50$ years & $169(29.3 \%)$ \\
\hline $51-60$ years & $128(22.2 \%)$ \\
\hline$>60$ years & $41(7.1 \%)$ \\
\hline \multicolumn{2}{|l|}{ PRM experience } \\
\hline$\leqslant 5$ years & $123(21.4 \%)$ \\
\hline $6-10$ years & $107(18.5 \%)$ \\
\hline $10-20$ years & $185(32.2 \%)$ \\
\hline$>20$ years & $161(27.9 \%)$ \\
\hline \multicolumn{2}{|l|}{ Academic degree } \\
\hline Resident/specialist registr & $91(15.8 \%)$ \\
\hline Specialist/consultant & $364(63.2 \%)$ \\
\hline Assistant professor & $28(4.8 \%)$ \\
\hline Associate professor & $45(7.8 \%)$ \\
\hline Professor & $48(8.4 \%)$ \\
\hline \multicolumn{2}{|l|}{ Institution } \\
\hline Tertia y cento university or training hospital) & $282(48.9 \%)$ \\
\hline Secona. ry center (state hospital) & $175(30.4 \%)$ \\
\hline Pri nar care & $33(5.8 \%)$ \\
\hline$\therefore$ in practice & $86(14.9 \%)$ \\
\hline pul tion of the city worked in & \\
\hline$>1000000$ & $236(40.9 \%)$ \\
\hline$>500000-1000000$ & $208(36.1 \%)$ \\
\hline Countryside $(<500000)$ & $132(23.0 \%)$ \\
\hline
\end{tabular}

PRM, physical and rehabilitation medicine.

dows, version 15.0 (SPSS Inc., Chicago, IL, USA). The data was treated in a descriptive and inferential manner. The categorical variables were presented as absolute values and percentages, and the numeric variables as means and standard deviations. The significance level was $p<0.05$.

\section{Results}

\subsection{Demographic data of the participants}

A total of 576 physiatrists participated in the survey. Approximately $60 \%$ of the participants were over 40 years old and had specialist PRM experience of more than 10 years. Most of the participants were PRM specialists or consultants. One-fifth of the participants had a university academic degree. Half of the participants worked at a tertiary center. The demographic characteristics of the participants are given in Table 1 .

\subsection{Assessment and management of the $L B P$}

Table 2 shows the rates of the responses to the 


\begin{tabular}{|c|c|}
\hline \multicolumn{2}{|l|}{$\begin{array}{c}\text { Table } 2 \\
\text { Survey data }\end{array}$} \\
\hline & $\begin{array}{c}\text { Participants } \\
(n=576)\end{array}$ \\
\hline \multicolumn{2}{|c|}{ Number of patients with LBP seen on average per week } \\
\hline$<5$ patients & $56(9.8 \%)$ \\
\hline $6-10$ patients & $107(18.5 \%)$ \\
\hline 11-15 patients & $111(19.3 \%)$ \\
\hline 16-20 patients & $85(14.7 \%)$ \\
\hline$>20$ patients & $216(37.6 \%)$ \\
\hline \multicolumn{2}{|c|}{ Percentage of patients with LBP given a clear diagnosis } \\
\hline$<20 \%$ & $56(9.9 \%)$ \\
\hline $20-39 \%$ & $90(15.8 \%)$ \\
\hline $40-59 \%$ & $167(29.3 \%)$ \\
\hline $60-79 \%$ & $175(30.8 \%)$ \\
\hline$>80 \%$ & $81(14.2 \%)$ \\
\hline \multicolumn{2}{|c|}{ Most valuable diagnostic tools in clinical assessment of LBP } \\
\hline History & $494(86.1 \%)$ \\
\hline Physical examination & $556(96.8 \%)$ \\
\hline Blood tests & $46(8.1 \%)$ \\
\hline $\mathrm{X}$-ray & $226(39.3 \%)$ \\
\hline MRI & $271(47.2 \%)$ \\
\hline Electrodiagnostic tests & $65(11.3 \%)$ \\
\hline \multicolumn{2}{|c|}{ Most commonly used or familiarity with LBP scales } \\
\hline Low Back Pain Rating Scale & $91(16.0 \%)$ \\
\hline Oswestry Disability Index & $206(36.2 \%)$ \\
\hline Progressive Isoinertial Lifting Evaluation & $0(0.0 \%)$ \\
\hline Quebec Back Pain Disability Scale & $27(4.75 \%)$ \\
\hline Rolland-Morris Disability questionnaire & $57(10.0 \%)$ \\
\hline None & $188(33.0 \%)$ \\
\hline \multicolumn{2}{|c|}{ Information relied on when treating a patient with LBP } \\
\hline International evidence-based medicine gu & $87(15.8 \%)$ \\
\hline Traditional clinical practice & $51(8.9 \%)$ \\
\hline Both & $435(75.96)$ \\
\hline \multicolumn{2}{|c|}{ Percentage of referrals to another clinical department } \\
\hline$<20 \%$ & $45 \cdot 8(20 \%$ \\
\hline $20-39 \%$ & $83(1 \div 6 \%)$ \\
\hline $40-59 \%$ & $103.3 \%)$ \\
\hline $60-79 \%$ & $8(1.43 \%)$ \\
\hline$>80 \%$ & $2(0.3 \%)$ \\
\hline \multicolumn{2}{|c|}{ Percentage of patients with LBP treated ac inp tients } \\
\hline$<20 \%$ & $409(72.5 \%)$ \\
\hline $20-39 \%$ & $71(12.6 \%)$ \\
\hline $40-59 \%$ & $41(7.3 \%)$ \\
\hline $60-79 \%$ & $20(3.5 \%)$ \\
\hline$>80 \%$ & $23(4.1 \%)$ \\
\hline \multicolumn{2}{|l|}{ Percentage of referrals for surgıcal treatment } \\
\hline$<20 \%$ & $542(95.2 \%)$ \\
\hline $20-39 \%$ & $25(4.4 \%)$ \\
\hline $40-59 \%$ & $2(0.3 \%)$ \\
\hline $60-79 \%$ & $0(0.0 \%)$ \\
\hline$>80 \%$ & $0(0.0 \%)$ \\
\hline
\end{tabular}

LBP, low back pain; MRI, magnetic resonance imaging.

questions in this survey. Half of the physiatrists involved in the study reported they are responsible for the management of at least 15 patients with LBP per week. Less than $15 \%$ of physiatrists were able to establish a clear diagnosis and cause of LBP for at least $80 \%$ of their patients. The most common pathologies in patients with LBP are lumbar disc herniation, in- tervertebral disc disease, spondylosis including facet degeneration, non-specific soft tissues injuries, spinal stenosis, and spondyloarthritis, in order of frequency (Fig. 1). History and physical examination remain the most valuable tools for the clinical assessment of LBP according to the participants. Among the LBP measurement scales, the physiatrists involved in the study were most familiar with the Oswestry Disability Index, the Low Back Pain Rating Scale, and the RollandMorris Disability Questionnaire, in order of popularity. Eighty percent of the participants did not request an MRI for more than half of their patients with LBP. Three-quarters of the physiatrists relied on both evidence-based guidelines and traditional clinical practice. Among the participant, $0 \%$ referred fewer than $20 \%$ of the patients wit $\triangle \mathrm{LBP}$ to another clinical department. Patients wer most often referred to neurosurgical departme ts, thllowed orthopedics, algologypain medicine rological and rheumatological departments, in o. de: of frequency (Fig. 2).

\subsection{Troctment of $L B P$}

Le, s than $20 \%$ of patients with LBP were treated inpatients. NSAIDs were the most frequently recommended drugs (Fig. 3). The most common nonpharmacological treatments recommended were exercise, back care information, and physical modalities, in order of frequency (Fig. 4). The physical modalities most frequently recommended to patients with LBP included superficial heating, low frequency TENS, therapeutic ultrasound, and interferential therapy, in order of frequency (Fig. 5). Around 40\% of the physiatrists in this study did not use interventional pain procedures in their clinical practice for LBP (Fig. 6). However, spinal injections and dry needling were the most frequently offered interventional treatments. Ninety-five percent of the physiatrists in the study reported that less than one-fifth of their patients with LBP were referred for surgical treatment.

\section{Discussion}

The present study is a preliminary report that presents the attitudes of European physiatrists to the low back pain. The results showed that physiatrists commonly dealt with patients with low back pain in their daily practice. Most of the patients were not referred to another department and treated with various conservative treatment methods. NSAIDs were the most com- 


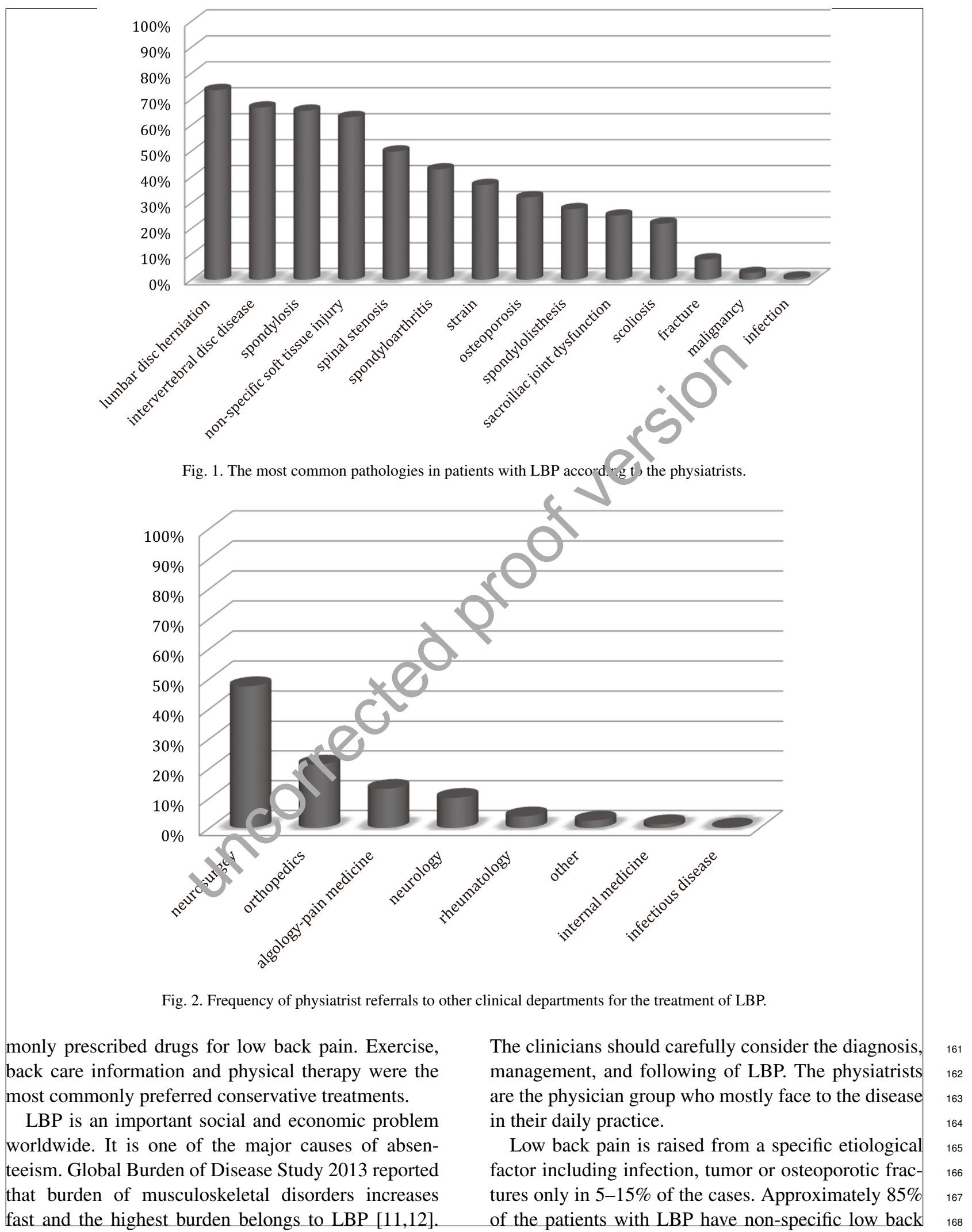


6 E. Dincer et al. / The approaches of physiatrists to low back pain

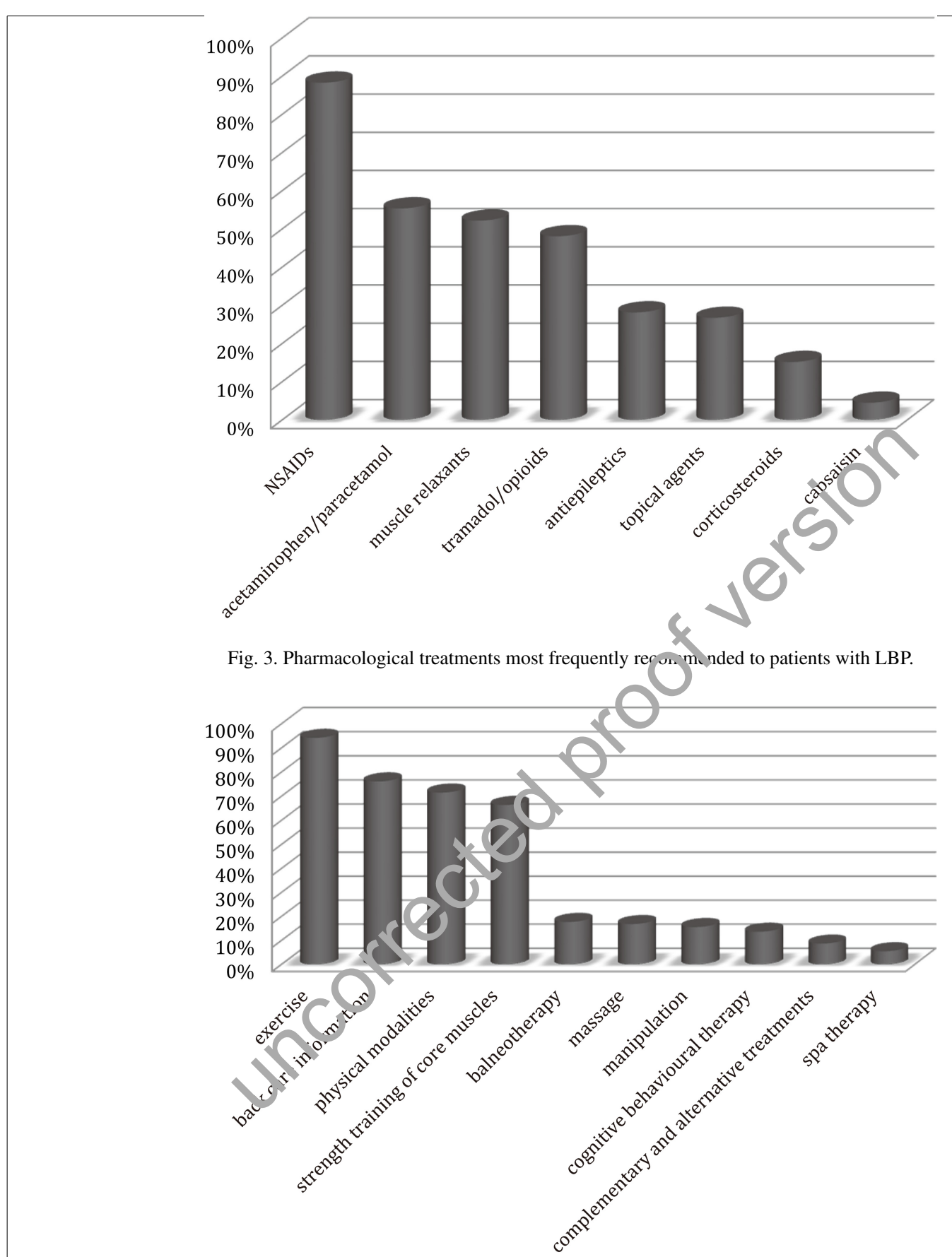

Fig. 4. Non-pharmacological treatments most frequently recommended to patients with LBP.

pain [13]. So, the diagnosis of the patients with LBP is a demanding process. Moreover, imaging findings and occurrence of low back pain are not strongly related [14]. So, the physiatrists focus on the discrimination of the patients with specific or non-specific LBP. Despite the evolving imaging techniques for spine, his- tory and physical examination is still the most valuable clinical evaluation tool for low back pain according to physiatrists. The results showed that the physiatrists believed that they could rarely establish a clear diagnosis accounting for low back pain.

The underlying mechanism of nonspecific LBP is 


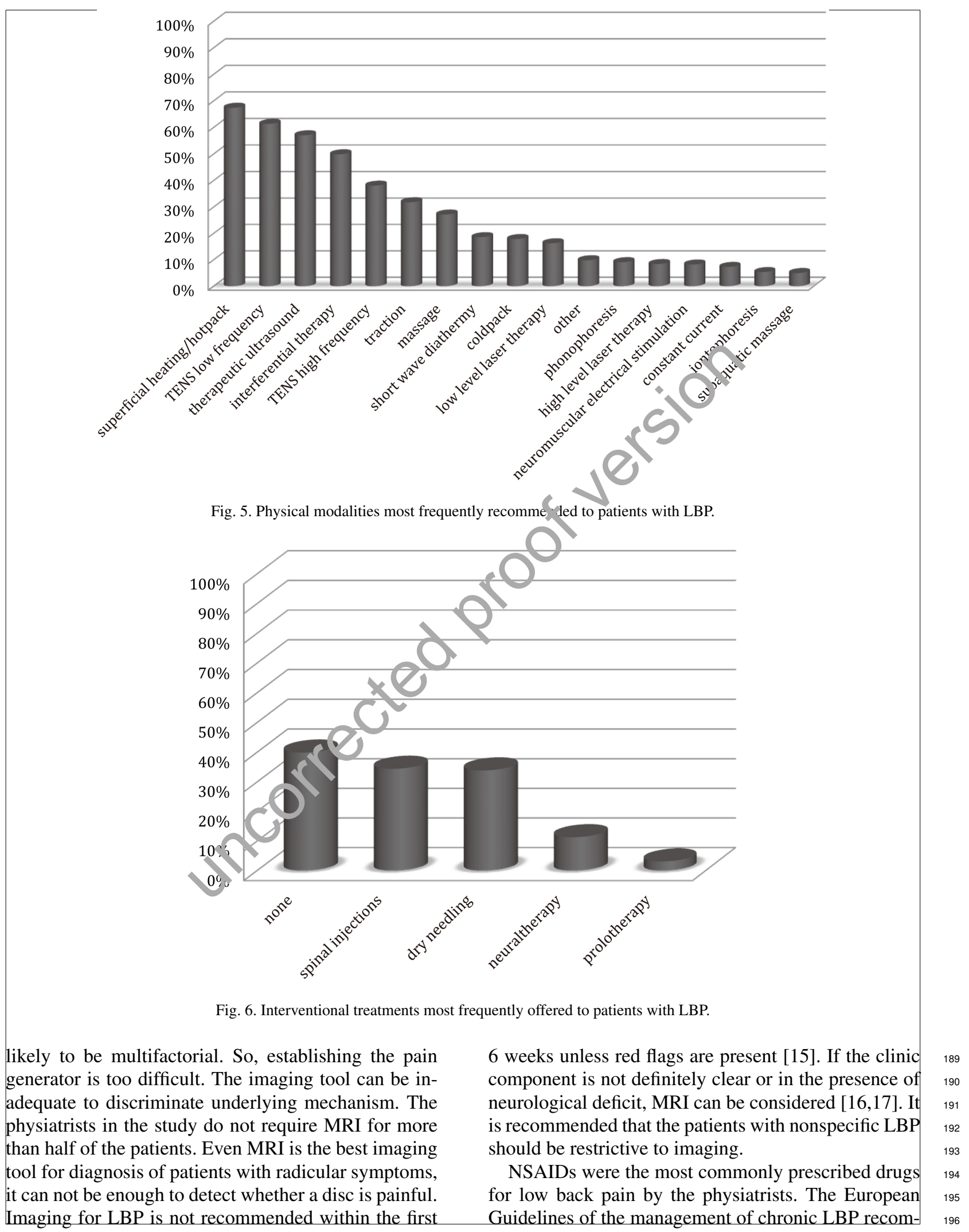


mends NSAIDs for pain relief in patients with chronic low back pain for short-term periods (up to 3 months) due to the side-effects [18]. In addition, new evidence shows that paracetamol seems as ineffective for low back pain [19].

Many non-pharmacological treatment modalities have been used for treatment of LBP such as exercise, behavioral therapy, spinal manipulation, acupuncture and physical therapy. Exercise, back care information and physical therapy were the most commonly preferred conservative treatments in this study. Exercise therapy is one of the most widely used treatments for LBP. It consists of a heterogeneous group of interventions ranging from general physical fitness to muscle strengthening, flexibility and stretching exercises or some other specific exercise. The Guidelines recommend supervised exercise therapy in patients with chronic low back pain [18]. Specific exercise regimens such as spinal stabilization exercises, McKenzie exercises and other specific exercise regimens are recommended to evaluate in the further.

Physical therapy is one of the most commonly preferred conservative treatments by the participants. However, there has been little evidence to support the use of most passive physical therapies (such as interferential therapy, short-wave diathermy, traction, ultrasound, lumbar supports, taping, and electrical musci stimulation) in the literature for low back pain [2 17. Exceptionally, superficial heat and low-level lase tilt $\mathrm{r}$ apy have been found more effective than ine sham treatment. Common risk factors for treatmont failure of the physical therapy including smo $\mathrm{k}$ ) workers' compensation status, night pain, an p.ychiatric history should be carefully evaluate $1, \mathrm{v}$ hen the management of LBP is considered [21).

Interventional pain treatm nt is another option in PRM practice for low ba $k$ pain. More than half of the physiatrists offer inte-entional treatments to their patients with low back pain. The patients who lack a strong indication for surgery, have advanced age or medical comorbidities that hindered the surgery, inadequate response to conservative treatment may be candidate for the interventional treatment. Spinal injections and dry needling were the most widely preferred techniques. The spinal injections consist of the techniques using fluoroscopic guidance such as epidural steroid injection, interlaminar approach, transforaminal approach, facet medial branch block and radiofrequency rhizotomy. Fluoroscopy-guided spinal injection treatments for chronic refractory low back pain have been reported safe, effective, and easy to perform interventions [22]
The physiatrist in the study reported that they referred rarely the patients with LBP to the surgical treatment. Surgery is a treatment approach that considered generally less than conservative treatment for LBP. In the literature, several randomized controlled studies that evaluated surgical or nonsurgical treatment found controversial results [23]. Appropriate patients for surgery may consult with surgeon. 5 .

\section{Conclusion}

Healthcare for patients with LBP is primarily provided by the physiatrists. Physiatrists with a widerange of academic degrees ar sc Europe participated in this study. It is a pr $111 \mathrm{n}$ inary report that presents the attitudes of Euronem physiatrists in the management of low back ain. The results showed that physiatrists commonl 7 e.lt with patients with low back pain in their daily p-otice. Most of the patients were not referre to anuther department and treated with various consu vative treatment methods. NSAIDs were the most conmonly prescribed drugs for low back pain. E. er ise, back care information and physical therapy vere the most commonly preferred conservative treatments. The physiatrists in the study reported that they rarely referred the patients with LBP to the surgical treatment. Surgery was generally considered less than conservative treatment for LBP. Exercise, back care information and physical therapy were the most commonly preferred conservative treatments in the study. The preferences in conservative treatment options may vary individually. Further researches are warranted to standardize the conservative management of LBP.

\section{Conflict of interest}

None to report.

\section{References}

[1] Urwin M, Symmons D, Allison T, Brammah T, Busby H, Roxby M, Simmons A, Williams G. Estimating the burden of musculoskeletal disorders in the community: the comparative prevalence of symptoms at different anatomical sites, and the relation to social deprivation. Ann Rheum Dis. 1998; 57: 649 655.

[2] Stranjalis G, Tsamandouraki K, Sakas DE, Alamanos Y. Low back pain in a representative sample of Greek population: analysis according to personal and socioeconomic characteristics. Spine (Phila Pa 1976). 2004; 29: 1355-1360 
[3] Hoy D, Brooks P, Blyth F, Buchbinder R. The Epidemiology of low back pain. Best Pract Res Clin Rheumatol. 2010; 24 769-781.

[4] Murray CJ, Vos T, Lozano R, Naghavi M, Flaxman AD, Michaud C et al. Disability-adjusted life years (DALYs) for 291 diseases and injuries in 21 regions, 1990-2010: a systematic analysis for the Global Burden of Disease Study 2010. Lancet. 2012; 380: 2197-2223.

[5] Vos T, Flaxman AD, Naghavi M, Lozano R, Michaud C, Ezzati $\mathrm{M}$ et al. Years lived with disability (YLDs) for $1160 \mathrm{se}-$ quelae of 289 diseases and injuries 1990-2010: a systematic analysis for the Global Burden of Disease Study 2010. Lancet. 2012; 380: 2163-2196.

[6] Fairbank JC, Pynsent PB. The Oswestry Disability Index. Spine (Phila Pa 1976). 2000; 25: 2940-2952.

[7] Manniche C, Asmussen K, Lauritsen B, Vinterberg H, Kreiner S, Jordan A. Low Back Pain Rating scale: validation of a tool for assessment of low back pain. Pain. 1994; 57: 317-326.

[8] Kopec JA, Esdaile JM, Abrahamowicz M, Abenhaim L Wood-Dauphinee S, Lamping DL, Williams JI. The Quebec Back Pain Disability Scale: conceptualization and development. J Clin Epidemiol. 1996; 49: 151-161.

[9] Roland MO, Morris RW. A study of the natural history of back pain. Part 1: Development of a reliable and sensitive measure of disability in low back pain. Spine. 1983; 8: 141144.

[10] Mayer TG, Barnes D, Kishino ND, Nichols G, Gatchel RJ, Mayer H, Mooney V. Progressive isoinertial lifting evaluation. I. A standardized protocol and normative database. Spine (Phila Pa 1976). 1988; 13: 993-997.

11] Moradi-Lakeh M, Forouzanfar MH, Vollset SE, El Bcheraou C, Daoud F, Afshin A, Charara R, Burden of musculoskeletaldisorders in the Eastern Mediterranean Region, 1990-2013. findings from the Global Burden of Disease Study 2013. A nn Rheum Dis. 2017; 76: 1365-1373.

12] Rasmussen-Barr E, Grooten WJA, Hallqvist J, 1 Skillgate E. Are job strain and sleep disturbance opro mostic factors for low-back painA? cohort study of a g neral population of working age in Sweden. J Rehabi Ne1. 2017; 49: 591-597.
[13] Deyo RA, Weinstein JN. Low back pain. N Engl J Med. 2001 344: 363-370.

[14] Van Tulder MW, Assendelft WJ, Koes BW, Bouter LM Spinal radiographic findings and nonspecific low back pain A systematic review of observational studies. Spine 1997; 22 : 427-434.

[15] Chou R, Qaseem A, Snow V, Casey D, Cross JT Jr., Shekelle $\mathrm{P}$, et al., Diagnosis and treatment of low back pain: a joint clinical practice guideline from the American College of Physicians and the American Pain Society. Ann Intern Med 2007; 147: 478-91.

[16] Allegri M, Montella S, Salici F, Valente A, Marchesini M Compagnone $\mathrm{C}$, et al. Mechanisms of low back pain: a guide for diagnosis and therapy. Version 2. F1000Res 5. 2016.

[17] Koes BWs, van Tulder MW, Thomas S. Diagnosis and treat ment of low back pain. BMJ. 2006; 332: 1430-1434.

[18] Airaksinen O, Brox JI, Cedraschi C, Hildebrandt J, Klaber Moffett J, et al. Chapter 4. Furopean guidelines for theman agement of chronic nonspe ific tow back pain. Eur Spine J. 2006; 15(Suppl 2): S19?-30 ?.

[19] Machado GC, Mahe o - Ferreira PH, Pinheiro MB, Li $\mathrm{CW}$, Day RO, et al - fricacy and safety of paracetamol for spinal pain anc oste arthritis: systematic review and metaanalysis of an ionised placebo controlled trials. BMJ. 2015 350: h1225.

[20] Chou K, r yo R, Friedly J, Skelly A, Weimer M, Fu R, et al. ystemic Pharmacologic Therapies for Low Back Pain As vs.ematic Review for an American College of Physicians Clir.ical Practice Guideline. Ann Intern Med. 2017; 166: 480 192.

21] Eleswarapu AS, Divi SN, Dirschl DR, Mok JM, Stout C, Lee MJ. How Effective is Physical Therapy for Common Low Back Pain Diagnoses? A Multivariate Analysis of 4597; Pa tients. Spine (Phila Pa 1976). 2016; 41: 1325-1329.

[22] Iannuccilli JD, Prince EA, Soares GM. Interventional spine procedures for management of chronic low back pain-a primer. Semin Intervent Radiol. 2013; 30: 307-317.

[23] Mirza SK, Deyo RA. Systematic review of randomized trials comparing lumbar fusion surgery to nonoperative care for treatment of chronic back pain. Spine (Phila Pa 1976). 2007, 32: 816-823. 